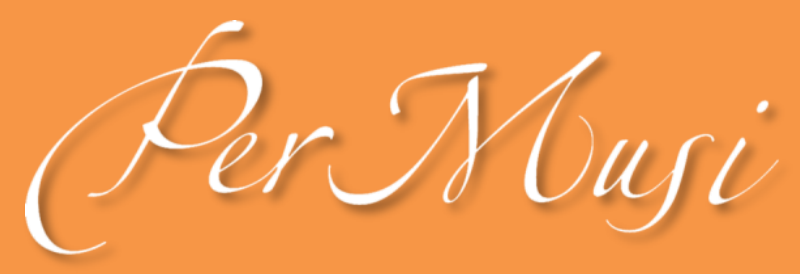

eISSN 2317-6377

\title{
Gesto Musical e Transcendência em Nigun, de Bloch
}

\author{
Edison Valério Verbisck \\ https://orcid.org/0000-0001-8524-2532 \\ Universidade Federal de Mato Grosso do Sul \\ edison.verbisck@ufms.br \\ Eduardo Lopes \\ https://orcid.org/0000-0002-6743-970X \\ Universidade de Évora \\ el@uevora.pt \\ SCIENTIFIC ARTICLE \\ Submitted date: 19 may 2021 \\ Final approval date: 17 jun 2021
}

Resumo: Ernest Bloch compôs em 1923 a obra Baal Shem: Three Pictures of Chassidic Life, constituída por três movimentos representativos do imaginário hassídico, respetivamente Vidui, Nigun e Simchas Torah. O segundo movimento tornou-se uma peça amplamente conhecida e incorporada ao repertório de violinistas. Bloch associa o nigun, interpretado pela voz humana, ao violino, colocando-o no lugar do Cantor ou Rabino. O violino incorpora o personagem orante que caracteriza o nigun, inclusive no gestual, utilizando a música como um veículo da materialidade para a transcendência (devekut). Através da análise expressiva, o presente ensaio pretende evidenciar as similaridades entre a composição Nigun e o género musical homónimo, ressaltando o gesto musical e a liberdade interpretativa, e despertar algumas reflexões sobre o tema, sem a pretensão de apresentar respostas definitivas ou conclusivas.

Palavras-chave: Ernest Bloch; Nigun; Gesto musical; Performance; Devekut.

\section{TITLE: MUSICAL GESTURE AND TRANSCENDENCE IN BLOCH'S NIGUN}

Abstract: In 1923, Ernest Bloch composed Baal Shem: Three Pictures of Chassidic Life. This musical work has three parts representing the Hasidic overground, respectively Vidui, Nigun and Simchas Torah. The second movement became a widely known piece and incorporated into the repertoire of violinists. Bloch associates the nigun, interpreted by the human voice, with the violin, putting the instrument in the place of the Cantor or Rabbi. The violin incorporates the praying figure that characterizes the nigun, including gestures, and using music as a vehicle from materiality to transcendence (devekut). Through expressive analysis, this essay aims to show the similarities between Bloch's Nigun and the homonymous musical genre, emphasizing musical gesture and interpretative cadential movement, and to awaken some thoughts about the theme, without the intention of presenting conclusive answers.

Keywords: Ernest Bloch; Nigun; Musical gesture; Performance; Devekut. 


\section{Gesto Musical e Transcendência em Nigun de Bloch}

Edison Valério Verbisck, Universidade Federal de Mato Grosso do Sul, edison.verbisck@ufms.br Eduardo Lopes, Universidade de Évora, el@uevora.pt

\section{1 - As paisagens sonoras de Ernest Bloch}

Ernest Bloch (1880-1959) foi um compositor suíço-americano com raízes familiares judaicas asquenazes. Estudou violino com Eugène Ysaÿe (1858-1931), e posteriormente voltou-se para a composição, tendo sido aluno de Iwan Knorr (1853-1916) e Émile Jaques-Dalcroze (1865-1950). Para além da música, Bloch tinha interesses variados, como a fotografia. São inúmeros os negativos atribuídos ao compositor, em sua maioria de paisagens e retratos, mas também situações cotidianas, fotografias de família e autorretratos.

Em 1923, Bloch compôs Baal Shem: Three Pictures of Chassidic Life ${ }^{1}$, música para violino e piano, inspirada na tradição hassídica e dedicada a figura de Baal Shem Tov (Rabi Israel ben Eliezer, 1698 - 1760), fundador do movimento místico denominado Hassidismo. A obra consiste em três andamentos, aos quais o compositor identificou com imagens da vida hassídica: Vidui (Contrição), Nigun (Improvisação), e Simchas Torah (Alegria).

A peça Nigun (1923) é a mais conhecida e incorporada ao repertório de grandes violinistas. Seu título é inspirado em uma forma de oração muito difundida na tradição judaica asquenaze, os nigunin, ou seja, canções sem palavras. A ausência de palavras é intencional, pois estas são impregnadas de significados que prendem o indivíduo ao mundo material, enquanto o que se pretende é a aproximação ao divino (Devekut). Bloch ainda Ihe atribuiu um subtítulo de "Improvisação", pois em sua composição há trechos que permitem (e exigem) essa liberdade ao intérprete.

O gesto musical e a "liberdade" interpretativa estão intrinsecamente relacionados nesta obra. Diante da performance do jovem prodígio Yehudi Menuhin (1916-1999), Bloch manifestou que a mesma representava a improvisação e o caráter interpretativo que ele imaginara ao compor Nigun. O gesto performático de Menuhin acabou por ser associado à composição, sendo uma referência aos intérpretes por conferir a sonoridade condizente ao texto e à imagem, na perceção do próprio compositor.

Assim, o Nigun concebido por Bloch possui células rítmicas repetitivas, com movimento acelerando, que procuram favorecer a transcendência, ao estilo do hassídico nigun - à semelhança de um movimento espiral crescente, que simboliza uma abertura da consciência e uma aproximação ao divino. Para além disso, podese também traçar um paralelo entre o gesto musical e o shuckling, uma forma de balanço para frente e para trás que visa potencializar a meditação, bastante comum entre os indivíduos adeptos do Hassidismo.

\footnotetext{
${ }^{1}$ Baal Shem: Três Retratos (Fotografias) da Vida Hassídica. [tradução livre]
} 
O presente ensaio pretende demonstrar a importância do gesto musical na obra Nigun, de Ernest Bloch, através da análise expressiva, entrelaçando-se algumas ideias sobre esse tipo de música hassídica assim denominada, bem como ressaltando o papel do movimento e do improviso no caminho para o Devekut.

\section{Nigun, o exílio das palavras}

O Hassidismo é um movimento místico do judaísmo, originário do Leste Europeu, aproximadamente da segunda metade do século XVIII. Baal Shem Tov é o fundador e expoente dessa corrente, que se espalhou rapidamente pelos judeus da diáspora. São heranças do Hassidismo, algumas ideias sobre silêncio e música, tais como: "Silence is better than words, but singing is better than silence"2, "There are castles in the upper spheres which open only to song"3 (Avenary 1964, 60). Um dos legados mais presentes do movimento hassídico, atualmente, é o género musical denominado 'nigun', utilizado em diferentes contextos.

'Nigun' é uma canção vocal e monofónica sem palavras, ou melhor, uma forma de oração musical com sons repetidos, que visa favorecer uma aproximação ao divino através de uma espécie de transe. A prática do 'nigun' é um conceito essencial e fundamental no Hassidismo. 'Nigun', neginah é a performance da música, enquanto menagen diz respeito ao intérprete (Seroussi 2017).

O movimento, e eventualmente a dança, podem estar associadas ao 'nigun'. Os vocábulos utilizados são foneticamente consistentes com o hebraico, russo e ídiche, idiomas falados pela maioria dos hassídicos do leste europeu. Além disso, essas sílabas possuem um significado espiritual, pois carregam em si as letras do nome de Deus (Rubin 2005).

Os nigunin (plural de 'nigun') servem como um prelúdio às orações ou preces, podendo ser empregues também como conclusão - e, eventualmente, algumas reuniões devocionais são inteiramente cantadas dessa forma! Percebe-se, assim, a importância da música para os judeus hassídicos. Está presente a noção do exílio, no qual as palavras também se encontram, e a prece cantada através do 'nigun' permite lentamente emergir das profundezas mundanas e procurar a transcendência (Avenary 1964).

A ideia subjacente a qualquer 'nigun' seria de que a alma, enquanto no mundo material, anseia por retornar à esfera de Deus, estando presente a conceção de fluxo. O movimento oscilante entre a materialidade e a transcendência, bem como os saltos surpreendentes como se o espírito saísse de um abismo, são representados na música (Seroussi 2017).

Os diferentes nigunin utilizam-se de técnicas que visam favorecer a ascensão da existência para a transcendência. Alguns exemplos de técnicas empregues são aumento da velocidade, mudanças rítmicas repentinas, aumento de tom. A música progride nesse caminho ascendente até atingir um ponto de clímax, que reflete a comunhão espiritual (devekut), retornando posteriormente à consciência, com a melodia voltando para um ponto mais baixo e encerrando o transe ou a inspiração divina (Walden 2012).

Existem três classes principais de 'nigunin', sendo elas: o canto solitário do rabino em busca do entendimento dos mistérios superiores; o individual, para buscar a comunhão com o Criador; e o coletivo utilizado em reuniões hassídicas. O 'nigun' não pretende seguir cânones artísticos, mas apenas pela participação e envolvimento dos membros é possível ocorrer o movimento interno, existindo um apelo à espontaneidade

\footnotetext{
2 "Silêncio é melhor que palavras, mas cantar é melhor que silêncio." [tradução livre]

3 "Há castelos nas esferas superiores que apenas se abrem às canções." [tradução livre]
} 
e ao improviso. Usualmente, não segue os padrões recitativos sinagogais, preferindo-se um estilo livre. A dança pode, eventualmente, estar associada ao 'nigun', pois é considerada um meio sagrado de expressão devocional (Avenary 1964).

O modo sinagogal Ahavah Rabbah Shteiger, que significa "Modo do Grande Amor de Deus", é utilizado nesse género musical (Figura 1). O nigun hassídico emprega um aumento gradual de altura na repetição obstinada do tema (motivos curtos), bem como mudanças abruptas ou aceleração contínua do tempo, e introdução de intervalos incomuns. As sílabas gaguejantes são interrompidas por exclamações de alegria ou pesar características muito comuns na música tradicional klezmer. Utilizam-se ritmos tensos e sincopados, sendo que esses elementos musicais visam reproduzir a ideia do movimento de ascensão gradual das profundezas para as esferas superiores (Avenary 1964).

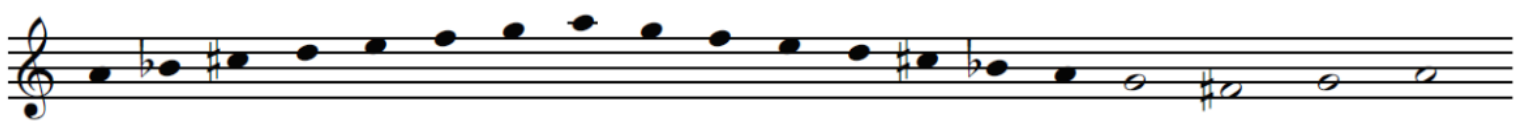

Figura 1: Escala Ahavah rabbah (Walden 2012, 796)

A dança é importante para os judeus do leste europeu, segundo a tradição, sendo inclusive obrigatória em alguns momentos, como a dança da noiva em casamentos. A dança circular é o exemplo mais claro de como os movimentos ritualizados fazem parte da cultura asquenaze (a qual os hassídicos, de modo geral, pertencem enquanto filiação ou região de nascimento). Assim como o idioma próprio, os falantes do ídiche possuem um vocabulário de gestos inerentes à sua tradição (Gollance 2019).

\section{O Nigun de Ernest Bloch}

Bloch concebeu seu Nigun com um referencial de gestos e linguagem dos judeus do leste europeu (os asquenazes), utilizando-se de géneros musicais e técnicas associadas à tradição hassídica. A opção pelo violino não se deve ao acaso: da mesma forma que o compositor escolheu o violoncelo para encarnar o personagem principal de "Schelomo: Rhapsodie Hébraïque for Violoncello and Orchestra"4(1915-1917), o violino é o personagem em "Baal Shem", que representa o judeu falante do ídiche. Ao imitar a voz humana, o violino apropria-se do idioma do hassídico e sua voz oscila entre a oração, o lamento e a alegria.

Antes da denominação como ficou conhecida a obra, Bloch considerou outros títulos como "Jewish Moods" e "Three Jewish Pieces", sendo o segundo movimento inicialmente chamado "Rhapsody". O Nigun de Bloch tem semelhanças e diferenças, relativamente ao género musical homónimo. Entretanto, o uso da escala Ahavah Rabbah, também conhecida como modo freygish, ressalta a intenção em associar essa música à prática dos hassídicos. O compositor realizou uma extensa pesquisa sobre melodias judaicas, as quais foram utilizadas em diferentes obras. Em Nigun, Bloch inspirou-se na oração Shoken Ad, do Sabbath Introit, e também em danças de casamentos e melodias de ocasiões festivas, como os freylekhs (Walden 2012). Para além disso, são características marcantes da peça, os intervalos de quintas e os ritmos pontuados, em passagens rapsódicas em modo fantasia (Kushner 2010).

Os traços judaicos intrínsecos à obra de Bloch foram delimitados por Knapp (1970-1971), reunidos em cinco categorias principais: melodia, ritmo, forma, textura e humor. Relativamente às melodias, emprega temas de casamento e escalas exóticas, incluindo passagens rapsódicas e quase improvisadas. Utiliza-se de

\footnotetext{
${ }^{4}$ Schelomo: Rapsódia Hebraica para Violoncelo e Orquestra. [tradução livre]
} 
intervalos melódicos de quarta e quinta perfeitas, em alusão à sonoridade do Shofar (instrumento de sopro utilizado no Templo), mas também incorpora a segunda e a quarta aumentada, e ocasionalmente uma inflexão de um quarto de tom.

O ritmo é um elemento importante na obra de Bloch, desde que o compositor estudou com Émile JacquesDalcroze, que desenvolveu um método de ensino da música baseado em movimentos corporais e gestos, denominado Euritmia. O compositor demonstra preferência por ritmos agudos e angulares, como o "lombárdico" e o "snap", bem como o uso da polirritmia. Neste sentido, desenvolveu uma forma própria de ritmo, o qual recebeu o nome de Bloch's rhythm (pode-se observar no primeiro compasso, na Figura 2), os padrões curto-longo semelhantes ao Scotch Snap (Kushner 2010).

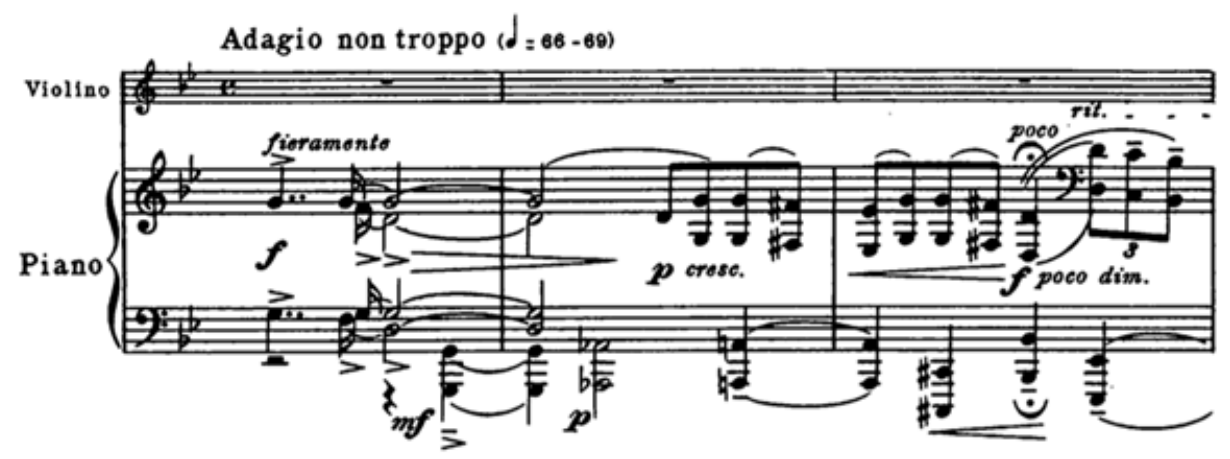

Figura 2: Bloch's rhythm, c.1-3 de Nigun (Bloch 2001, 30)

Quanto à forma, embora siga os cânones da música erudita ocidental, decorrente de sua sofisticada formação europeia, não deixa de recorrer aos sons exóticos e aos extremos do alcance instrumental. As texturas sinfónicas também estão presentes, pelo uso alargado de instrumentos de sopro, metais e percussão. O humor, ou o clima geral de sua obras, oscila entre o melancólico e o excitado, o pessimista e o otimista, e assim por diante. É uma marca autobiográfica do compositor a utilização de expressões como "frenético" ou "misterioso" (Knapp 1970-1971). Particularmente em Nigun, na parte para violino, Bloch emprega as expressões emocionais fieramente, lamentoso, maestoso e dolcissimo, às quais correspondem gestos musicais e texturas que caracterizam a obra.

O Nigun, de Bloch, foi repetidamente executado em concertos e gravado por muitos violinistas entre 1920 e 1960, de modo particular, ressaltando musicistas de renome como Menuhin, Szigeti, Elman, Milstein. Cada um destes intérpretes incorporou elementos expressivos e gestos de liberdade que conferem um caráter personalizado à composição. Por exemplo, a interpretação de Szigeti, diferentemente de Menuhin, utiliza as passagens livres e cadenciais para incluir elementos técnicos de virtuosismo, bem como evocar elementos da música klezmer. Sua interpretação é mais rápida e enérgica e possui aproximadamente 2 minutos a menos que a gravação de Menuhin. Entretanto, ambas representam igualmente bem o caráter judaico e a “improvisação" pretendida pelo compositor, tão relevantes na obra Nigun. Sendo assim, a análise expressiva favorece a incorporação do sentido musical e dos gestos de liberdade dos performers à composição, reforçando seu caráter autêntico.

\section{O gesto musical e a busca da transcendência}

A análise musical, enquanto disciplina académica, concentra-se nos aspetos formais da teoria da música, e comumente ignora os significados expressivos de uma obra, como o gesto musical. A expressão emocional 
não é o objetivo central de todas as composições, embora seja um elemento essencial em muitos casos. A análise expressiva, contudo, nada mais é do que a perceção de um sujeito sobre o significado expressivo da música. Albrecht (2018) questiona-se sobre quem teria o "direito" ou a "capacidade" de melhor avaliar a componente expressiva, se seria o ouvinte comum, se seria o estudioso de musicologia, ou qualquer outra pessoa. Em qualquer caso, coloca-se o aspeto da intersubjetividade, sendo, portanto, uma tentativa de generalização a partir de impressões de um ou dois indivíduos, mesmo com algum embasamento teórico. Portanto, um ensaio sobre o gesto musical e a componente expressiva de uma obra pretende demonstrar os motivos subjacentes a essas impressões, cabendo uma avaliação posterior do leitor/ouvinte.

Uma compreensão ecológica ${ }^{5}$ da performance musical inicia-se pelo corpo e resulta num movimento intencional. O gesto é bastante importante em composições de caráter expressivo, como o Nigun, de Bloch. O movimento, inclusive, é tão ou mais relevante que o som resultante, uma vez que, em alguns casos, há gestos que não produzem uma sonoridade diferente (Östersjö 2016).

Conforme Hatten (2010) sugere, na música têm-se gestos, tópicos e tropos. Os gestos musicais são construídos a partir da partitura e da interpretação, podendo surgir espontaneamente ou intencionalmente, e assumindo uma função temática, dialógica, retórica e/ou tropológica com a obra. Tópicos são figuras características como danças, géneros, texturas, que passam a fazer parte da trajetória dramática com um género expressivo. Tropos são interações ou fusões de tipos estilísticos incompatíveis, que são reunidos num contexto específico e adquirem um significado que emerge dessa interação particular.

Embora essa conceituação seja relevante, os gestos, tópicos e tropos estão interligados na interpretação musical, conforme o significado atribuído, e atuam de forma conjunta para criar uma atmosfera própria. No caso do Nigun, de Bloch, cria-se um ambiente introspetivo de oração hassídica, que pela sua natureza não é estática e limitada à partitura, permitindo movimentos de uma certa liberdade por parte do intérprete. Portanto, a compreensão do gesto musical refere-se sobretudo ao aspeto performático (por exemplo, através da "improvisação"), sem descuidar da intenção do compositor ou daquilo que é capaz de despertar no ouvinte.

A peça, portanto, possui 108 compassos divididos em quatro seções, e sua execução dura aproximadamente 6'40 minutos (entre 5'30 e 8 minutos, conforme a performance). Na primeira seção (compassos 1 a 23), há a exposição do primeiro tema apresentado pelo violino, motivo que determina o caráter melancólico da obra. Encontram-se as expressões de dinâmica "fieramente" (algo como "orgulhosamente") e "lamentoso", como elementos a serem considerados na interpretação. $O$ gesto interpretativo, devido ao ethos lamentoso que caracteriza essa seção, requer o uso de glissandos no violino. O movimento de deslizar os dedos entre as mesmas notas, no violino, tem como finalidade imitar a expressão vocal. A primeira parte inicia-se em Sol menor, com uma modulação para Sib Maior no compasso 16, servindo como a primeira imagem introdutória da obra e preparando a segunda seção com o tema principal na escala de Ahavah Rabbah.

O violino apresenta as primeiras passagens livres em forma de "cadenza" (compasso 14), que fazem salientar o caráter gestual de alguma liberdade, com o uso de "accelerandos" e "allargandos" indicados pelo compositor (Figura 3). Além disso, há ocorrência de padrões rítmicos (colcheias, tercinas, semicolcheias) com ${ }^{5}$ Conceito proposto pelo psicólogo James Gibson, segundo o qual o sistema percetual resulta de um
envolvimento ativo do ser humano (Östersjö 2016). 
progressiva aceleração no andamento, permitindo liberdade interpretativa, nos compassos seguintes (Figura 4).

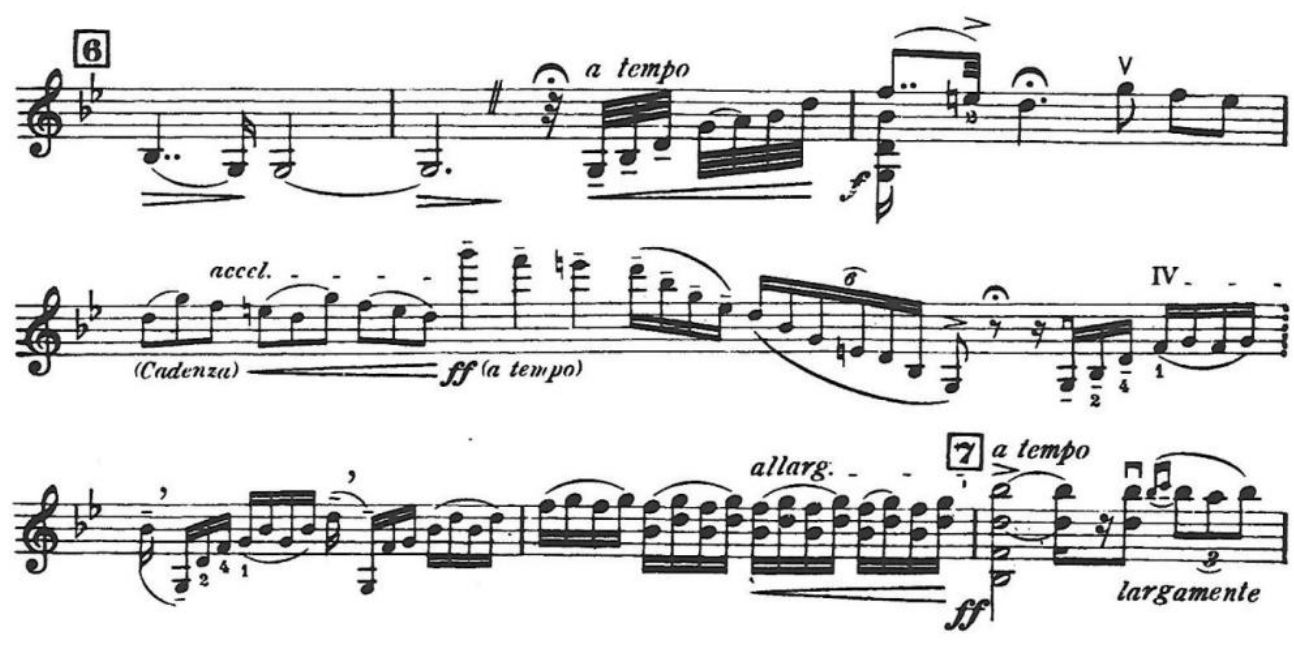

Figura 3: Cadenza, c.11-16 de Nigun (Bloch 2001, 13)

Observa-se aqui uma possível associação entre o movimento accelerando, na música, e o movimento corporal do orante. A prece do judeu normalmente é realizada em pé, além de muito frequentemente incluir alguma forma de movimento, como um balanço para frente e para trás, ou ainda para a esquerda e para a direita. O balanço, muito comum entre os hassídicos, é chamado de shuckling (Lazar 2017). Segundo Gollance (2019), o gestual das mãos é característico da tradição judaica, particularmente ídiche. O movimento de abençoar as velas no Sabbath, a forma de fazê-lo ao balançar as mãos, é repetido enquanto gesto de dança também.

a)

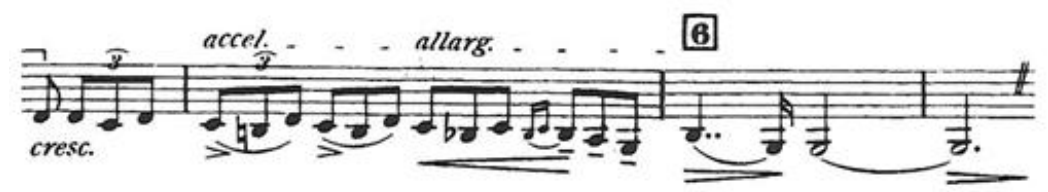

b)

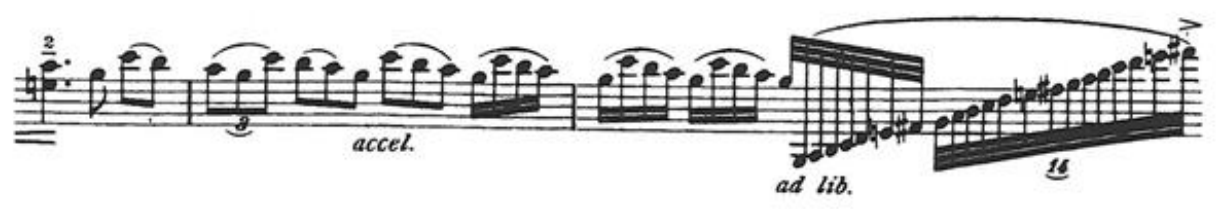

Figura 4: Exemplos de ad lib a) c.9-12, b) c.19-20, Nigun (Bloch 2001, 13)

No início da segunda seção (compassos 24-37), o piano antecipa os gestos musicais. O violino, na sequência, repete a melodia na forma de imitação, dando um efeito de eco e conferindo maior profundidade à música. A melodia inicialmente exposta pelo piano está na escala Ahavah Rabbah, e no acompanhamento está um conjunto de tercinas que soam como arpejos, numa pulsação constante e repetitiva (compasso 24-29, conforme Figura 5) que nos remete ao shuckling. 


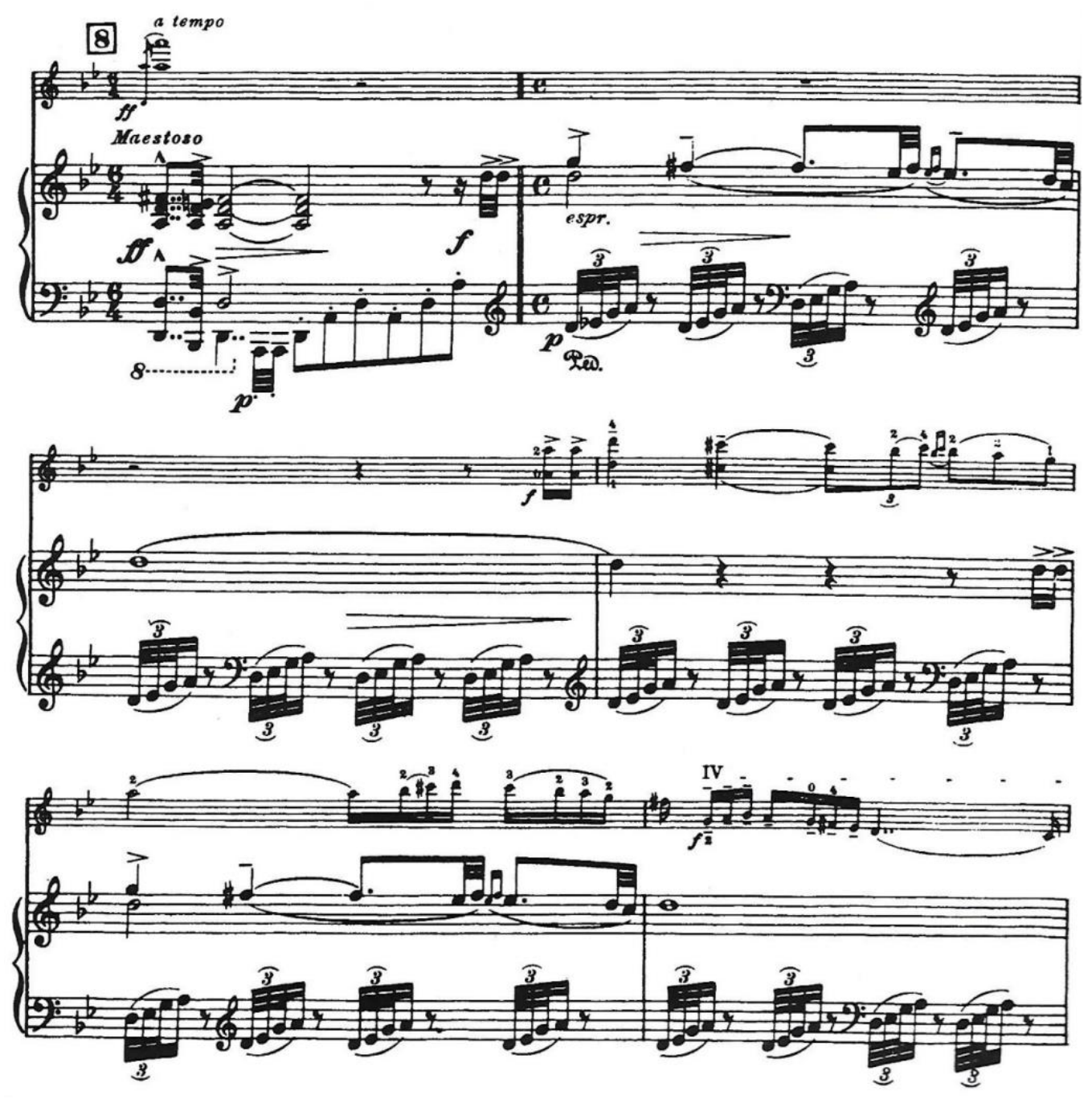

Figura 5: Padrões rítmicos repetitivos, c.23-28 de Nigun (Bloch 2001, 32)

O violino, por sua vez, apresenta o primeiro tema com a indicação "forte", no que se refere à interpretação, com as quatro primeiras notas executadas em oitavas, dando ênfase à melodia anteriormente exposta pelo piano, com a presença marcante da segunda aumentada. Novamente há espaço para um gesto cadencial nos compassos 35-36 (Figura 6), pois o acompanhamento do piano é suspenso e o violino executa uma escala descendente. Conclui com um tetracorde descendente da escala Ahavah Rabbah na IV corda do violino, conduzindo para a abertura da terceira seção.

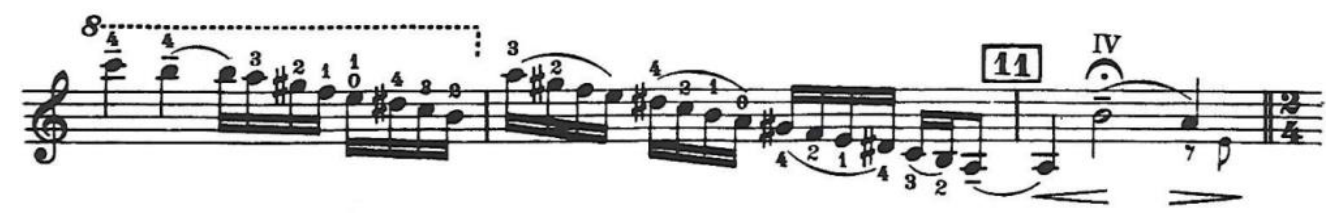

Figura 6: Cadenza, c.35-36 de Nigun (Bloch 2001, 14)

Neste trecho, o compositor cria uma expectativa, e depois a "frustra", causando alguma dúvida sobre o que esperar a seguir. Segundo Albrecht (2018), as emoções mais fortes seriam evocadas a partir de passagens musicais menos previsíveis, ou seja, a expetativa desempenha um papel fundamental na forma como a música gera emoção. Por exemplo, uma passagem que sirva para atrasar a resolução esperada, retornando ao tema principal em vez de chegar ao desfecho, pode causar uma emoção extrema pela quebra da expectativa. 
Logo no princípio da terceira parte, o compositor regista a indicação "dolce espressivo", na qual o piano reapresenta a melodia, e o violino desenvolve-a num crescente até o ápice, que ocorre no compasso 76 (Figura 7). Predominam os acordes de quatro notas, com a indicação dinâmica de forte, a partir do compasso 48. Observa-se um paralelo de padrões rítmicos usados no nigun hassídico, que utiliza sílabas repetidas como "bam-bam-bam", fazendo uso de células rítmicas em ritmo acelerando (compassos 56-60) e com a presença de ritmos sincopados (compassos 64-67), conforme o Figura 8.

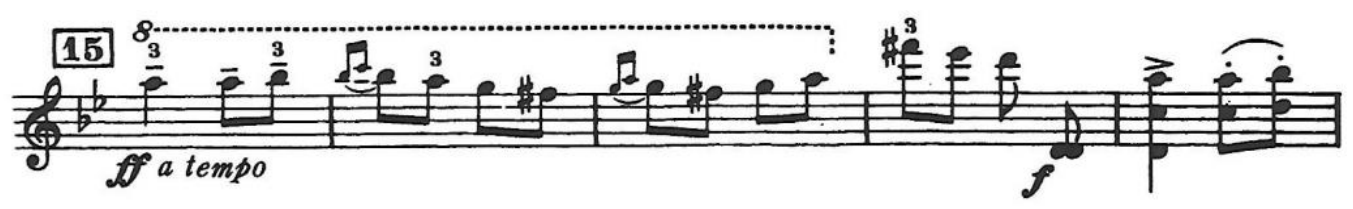

Figura 7: Ápice, c.76-79 de Nigun (Bloch 2001, 15)

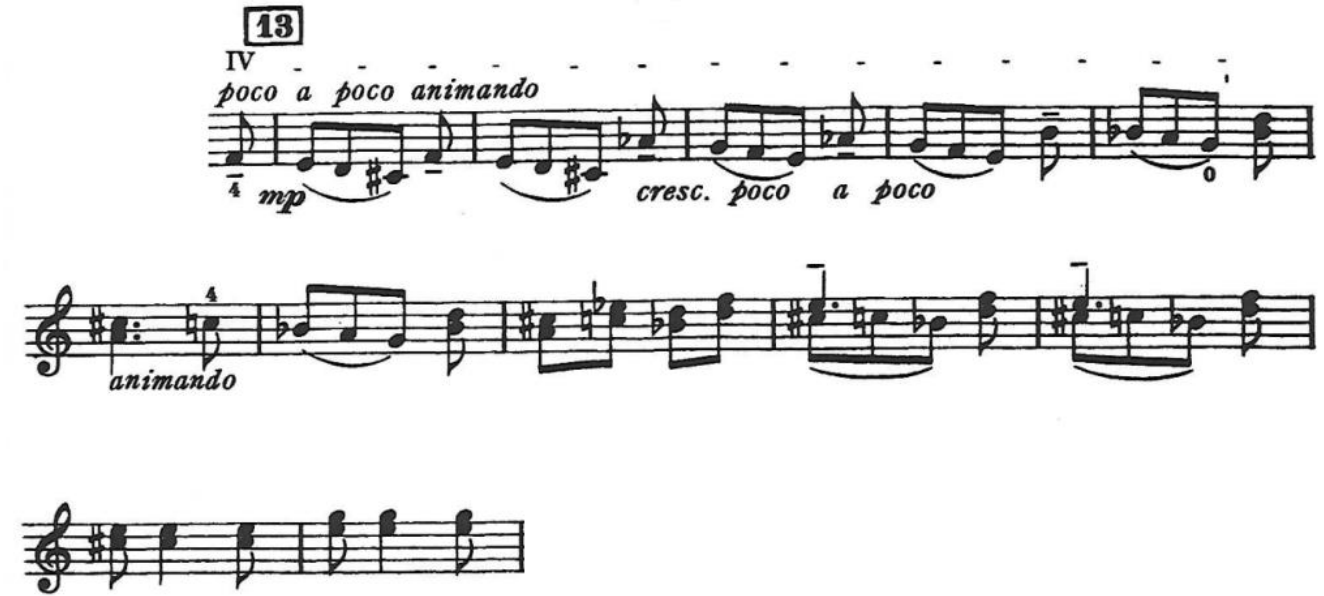

Figura 8: Ritmo, c.56-67 de Nigun (Bloch 2001, 15)

O violino executa um gesto de jogar o arco nas cordas, assemelhando-se ao krekht, técnica utilizada no klezmer, que reforça o caráter interpretativo da obra. Na medida em que se movimenta para o ápice (devekut), o Nigun de Bloch apresenta maior instabilidade harmónica e maior cromatismo. O momento do clímax é breve, e na música é executado em regiões agudíssimas do violino, com a indicação de fortíssimo. Na sequência deste momento, o desenho melódico e a dinâmica começam gradativamente a decair até a passagem livre escrita na oscilação de duas notas, com uma nova passagem de gesto de alguma liberdade (compasso 87, Figura 9) que estabelece o início para a última seção.

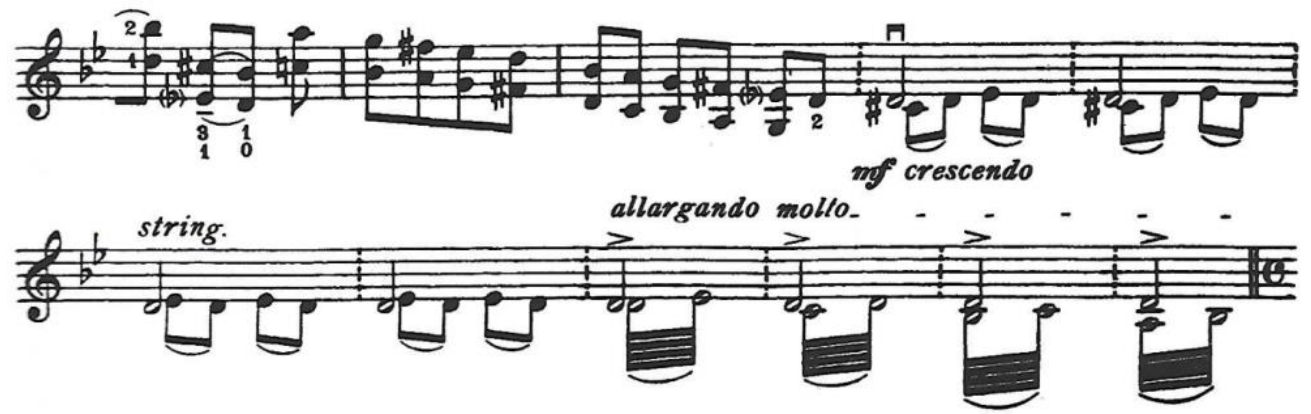

Figura 9: Gesto de liberdade, c.85-87 de Nigun (Bloch 2001, 15) 
A quarta parte inicia-se com o violino a apresentar o tema inicial numa oitava acima, e o compositor retoma o gesto inicial, não mais "lamentoso" (como no princípio), mas com a indicação "fortíssimo", além da presença de acordes, oitavas e intervalos de terças no violino. Há uma analogia ao gesto do hassídico orante, que ao passar pelo devekut, volta para a sua realidade inicial com uma perceção renovada da realidade. A última seção de Nigun é uma reexposição da primeira, entretanto com passagens que destacam o virtuosismo do violino. Logo no compasso 97 (Figura 10), observa-se uma passagem cadencial com compasso sem mensuração, acelerando e alargando dentro do mesmo compasso, permitindo um movimento de alguma liberdade.

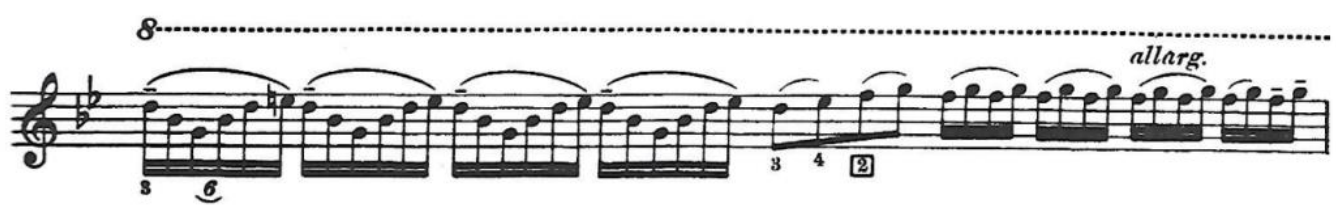

Figura 10: Passagem cadencial, c.97 de Nigun (Bloch 2001, 16)

A peça culmina na coda (compassos 102-108, Figura 11), que retorna para a escala Ahavah Rabbah. O gesto melódico aqui desenvolvido é três vezes apresentado, em oitavas cada vez mais agudas, mas sempre com a indicação de uma dinâmica mais suave e lenta, progressivamente, terminando com um harmónico natural na nota Ré, tocado na corda Sol do violino. Este gesto musical nos remete para o repouso e a preparação para a enérgica sequência da obra "Baal Shem", em seu último movimento.

Todo movimento do corpo ou de parte dele, que seja imbuído de significado expressivo, pode ser considerado um gesto, desde que carregue em si uma intencionalidade, um grau de voluntarismo. $O$ gesto caracteriza uma experiência estética, sendo também causador e resultante de uma interação social (Schleifer 2019).

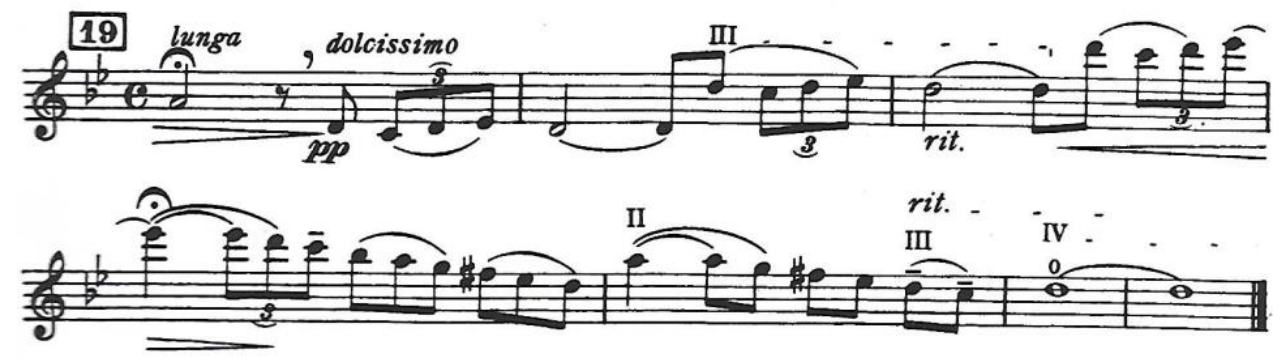

Figura 11: Coda, c.102-108 de Nigun (Bloch 2001, 16)

Deve-se ainda ressaltar a importância do improviso (na conceção do termo segundo o próprio compositor), bem como alguns gestos de liberdade introduzidos pelos intérpretes, particularmente Yehudi Menuhin. A expressividade é um aspeto essencial na obra, pois ressalta uma intenção de Bloch nesta composição. $O$ nigun entoado pelo rebbe ou pelo Cantor permite variações livres durante sua interpretação, conforme critérios próprios e pelo movimento do grupo orante, na busca do devekut. Assim, Bloch registou esses momentos de "improvisação" em sua partitura, conferindo ao intérprete uma liberdade gestual a partir do texto escrito. As indicações cadenza e ad lib em alguns trechos, permitem ao violinista uma flexibilidade no gesto interpretativo, sendo possível incorporar o rubato, alterando ligeiramente o tempo, acelerando ou desacelerando-o. 
Nos compassos 21-22 e 35-36, o compositor delimita o tom e a duração, mas omite as barras de compasso (utiliza barras pontilhadas), deixando o ritmo livre. São partes sem o acompanhamento do piano, que permitem ao violinista gestos expressivos de liberdade e espontaneidade, condizentes com o nigun hassídico. Relativamente aos gestos performáticos, os intérpretes de Nigun incorporaram elementos expressivos próprios, decorrentes da sua compreensão da obra.

Yehudi Menuhin criou uma interpretação tão marcante e significativa, que passou a ser modelo para os demais violinistas, além de ter reforçado o caráter autêntico da peça. O compositor manifestou em determinado momento que sua interpretação e o caráter improvisatório representavam exatamente o que ele imaginara ao compor Nigun. Seu estilo quasi-teatral faz memorar o hassídico a cantar/orar. Menuhin aumenta o peso da primeira nota, para acentuar um movimento de suspiro. Também utiliza o vibrato e o glissando em várias velocidades, além de modular o ritmo e manter o tom por mais tempo que o esperado, a fim de intensificar o efeito melancólico (Walden 2012). Os gestos de alguma liberdade devem ser integrados pelos intérpretes, conforme sua perceção relativamente ao background da composição, bem como aos sentimentos despertados no musicista. Yehudi Menuhin manifestou-se a respeito: "The violinist should be allowed to express a degree of intuition [...] The violinist seems to live and move in the empty spaces between notes and transforms and fashions them in accordance with his own and the listener's sensibilities" $^{6}$ (Menuhin, citado por Walden 2012, 814). A obra de Bloch convida o intérprete a incorporar elementos pessoais na execução, e Menuhin o fez largamente através do rubato, dos glissandos e de outros elementos que reforçam seu envolvimento pessoal com a composição.

Para Cook (1999), a melhor abordagem da partitura seria percebê-la como um script ou roteiro apenas, conferindo ao intérprete uma certa liberdade para desempenhar a obra considerando outros elementos, tais como interações sociais. Os performers alegam, por exemplo, que para ressaltar a expressividade da composição é necessário fazer uso de técnicas como tempo rubato. É o caso de Menuhin, em sua interpretação de Nigun, por exemplo nos compassos 14-16 (retoma o exemplo da Figura 3), quando "rouba" um pouco do tempo para compensá-lo a seguir. Por esse motivo, a análise interpretativa permite uma compreensão abrangente do sentido musical e das contribuições dos intérpretes na consolidação de uma composição repleta de significados, como é o caso do Nigun de Bloch.

\section{Devekut}

O Nigun de Bloch, embora visto aqui como uma peça isolada, faz parte de uma história que retrata elementos representativos da vida hassídica. Ao conceber "Baal Shem: Three Pictures of Chassidic Life", o compositor utilizou um referencial de imagem, pela sua ligação com a fotografia enquanto forma de expressão e apreensão do mundo. De fato, Bloch é um compositor extremamente visual, sempre associando sua obra à imagem, seja implícita ou explicitamente, como em "Schelomo", por exemplo.

O andamento inicial, Vidui (Contrição), possui um tom introspetivo, no qual sente-se a preparação do judeu para a oração. Ao longo do Nigun, realiza-se a oração cantada sem palavras e a conexão com a esfera superior (devekut), preparando o momento de encontro com a Torah. A alegria do judeu em aproximar-se da palavra sagrada é festejada no Simchas Torah, o terceiro andamento. A compreensão dessa história

6 "O violinista deve ter permissão para expressar um certo grau de intuição [...]. O violinista parece viver e se mover nos espaços vazios entre notas e os transforma e molda conforme sua própria sensibilidade e a do ouvinte." (Menuhin, citado por Walden 2012, 814) [tradução livre] 
apenas reforça a ideia do devekut como um meio, e não um fim último no processo religioso do hassídico, do judeu orante, e provavelmente do próprio Baal Shem Tov, na idealização do compositor.

A palavra devekut, do ídiche dveykes, significa comunhão com o Transcendente, e aparece inúmeras vezes em sermões e ensinamento hassídicos. Entretanto, há uma intensa discussão sobre o conceito de devekut entre os estudiosos da área. Atualmente, é mais amplamente aceite que não há uma conceção unidimensional, e que para além da conexão com Deus, o termo pode também identificar estados de intensa concentração ou de apego ao divino. Trata-se de uma experiência individual que, para alguns, pode significar uma experiência de viver com Deus, enquanto para outros representa o temor do paraíso (Mayse e Reiser 2018).

O caminho para a transcendência é uma experiência individual. Entretanto, o nigun serve como um reservatório (ou um recetáculo) para favorecer o processo individual e coletivo. Embora o processo seja íntimo e particular, o nigun enquanto experiência comunitária recebe um impulso adicional através do movimento e, eventualmente, da dança (Seroussi 2017).

$\mathrm{Na}$ imagem (Figura 12), uma fotografia de Bloch, vê-se uma paisagem com uma montanha e nuvens. Ernest Bloch, além de compositor, era um fotógrafo amador. Algumas fotografias suas, por exemplo, consistem em imagens de árvores, e receberam nomes de compositores, como Bach - a partir de uma perceção do próprio compositor e fotógrafo, que registou a legenda sem maiores explicações. A figura proposta foi uma fotografia realizada pelo compositor em Chatêl, França, no ano de 1935. Para os autores do artigo, poderia perfeitamente servir como analogia para o orante, em pé como uma montanha, e o processo de transcendência acima dele, em direção ao superior. Propõe-se um paralelo com a obra Nigun e o movimento do próprio compositor, em busca de um sentido transcendente.

Os gestos musicais reproduzem uma forma de comportamento humano que liga o sujeito ao meio exterior. Os ritos e ritmos ajudam o indivíduo a estabelecer interações sociais, a comunicar-se e a situar-se (Marothy 1993-1994). No processo de transcendência, há o desligamento da materialidade e a busca da conexão com o superior.

A obra de Bloch é pautada pela autenticidade e expressividade. A análise musical e técnica, realizadas de uma forma academicamente normativa, acaba por ser pouco representativa. O próprio compositor rejeitava a ideia do virtuosismo sem sentido, que pouco teria a ver com seu trabalho. Na primeira metade do século $X X$, Bloch observou o crescente interesse por composições cerebrais, que refletiam uma obsessão dos compositores por técnica e procedimento. Entretanto, ele persistia em sua construção de uma música que emanasse de uma raça, de um povo - uma forma de expressão da alma. Além disso, valorizava o artista, dando-lhe indicações, em suas composições, para que o intérprete tivesse seu frescor de sensações e pudesse executar uma obra com sinceridade e liberdade. Dessa forma, o compositor incluía espaços para que o intérprete tivesse seus gestos de alguma liberdade (cadenza, ad lib), prevendo momentos de expressividade, essenciais para o sentido musical de sua obra (Bloch e Frank 1933).

Program music? Let it be! The essential thing is that musical logic be observed... I have done my best in that direction. Moreover, most of my works have been inspired by a poetic or philosophical idea, even sometimes unconsciously. Art for me is an expression, an 
experience of Life, and not a jigsaw puzzle or an application in cold blood of mathematical theories - a laboratory dissection. (E. Bloch, citado por S. Bloch 1976, 71). ${ }^{7}$

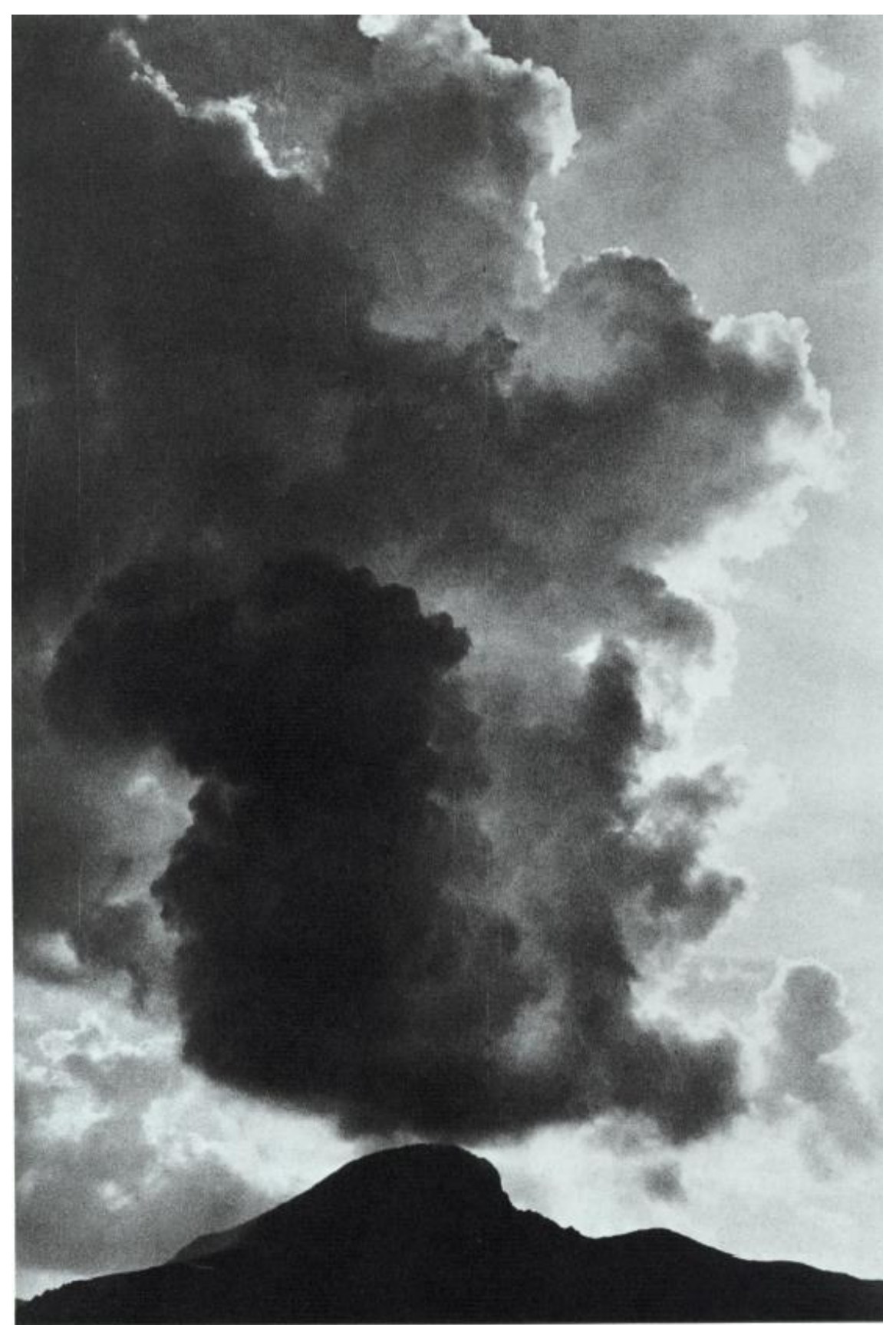

Châtel, France 1935

Figura 12: Fotografia de Bloch (Johnson 1972, 3)

Pensar sobre o gesto musical em Bloch é bastante pertinente, pois a "improvisação", da forma concebida pelo compositor ao escolher esse subtítulo, faz parte da essência do Nigun, uma vez que associa a composição ao género de oração hassídica, e ao movimento típico do judeu orante. O caminho para a

\footnotetext{
7 “Música programática? Deixe estar! O essencial é que a lógica musical seja observada [...]. Tenho feito o meu melhor nesse sentido. Além disso, a maioria de minhas obras foi inspirada por uma ideia poética ou filosófica, às vezes até inconscientemente. Arte para mim é uma expressão, uma experiência de vida, e não um quebra-cabeça ou uma aplicação a sangue frio de teorias matemáticas - uma dissecação de laboratório." (E. Bloch, citado por S. Bloch 1976, 71) [tradução livre]
} 
transcendência não é linear, não é único, incluindo alguns elementos de espontaneidade e outros "inconscientes". A canção serve como um veículo para a ascensão, e assim o compositor conseguiu reproduzir essas ideias na sua obra Nigun. O gesto musical para Bloch deve estar permeado de um sentido humano e artístico que supere a interpretação puramente mecânica, que recairia em um virtuosismo estéril. A arte para Bloch parte do movimento humano que está envolvido na expressão pessoal e interpessoal, retrato de uma cultura subjacente ao próprio gesto artístico.

O devekut no nigun é o ápice, mas não representa o fim de um processo, pois é uma parte desse movimento espiral. Neste artigo, levantam-se questões sobre o tema do gesto musical em Nigun, de Bloch, mas não se pretende oferecer respostas. As conclusões seriam demasiado reducionistas para um tema que aborda impressões sobre uma composição e suas interpretações. As análises refletem o caminho dos autores na compreensão da obra, sendo agora papel do leitor/ouvinte dar continuidade ao fluxo e construir suas próprias reflexões.

\section{Referências}

Albrecht, Joshua. 2018. "Expressive Meaning and the Empirical Analysis of Musical Gesture: The Progressive Exposure Method and the Second Movement of Beethoven's Pathetique Sonata". Music Theory Online, 24 (3). Disponível em: https://mtosmt.org/issues/mto.18.24.3/mto.18.24.3.albrecht.html

Avenary, Hanoch. 1964. "The Hasidic Nigun. Ethos and Melos of a Folk Liturgy". Journal of the International Folk Music Council, 16: 60-63. Disponível em: 10.2307/835078.

Bloch, Ernest. 2001. "Baal Shem". Music for Violin and Piano. Nova lorque: Carl Fischer: 27-45.

Bloch, Ernest, e Waldo Frank. 1933. "Man and Music". The Musical Quaterly, 19 (4): 374-381. Disponível em: http://www.jstor.org/stable/739062

Bloch, Suzanne. 1976. Ernest Bloch: Creative Spirit. New York City: Jewish Council of the Jewish Welfare Board.

Cook, Nicholas. 1999. "Analysing Performance and Performing Analysis". Rethinking music. Eds. Cook, N., \& Everist, M. Oxford: Oxford University Press: 239-261.

Gollance, Sonia Beth. 2019. "Gesture, Repertoire, and Emotion: Yiddish Dance Practice in German and Yiddish Literature". Jewish Social Studies: History, Culture, Society, 25 (1) Disponível em: 10.2979/jewisocistud.25.1.04

Hatten, Robert. 2004. Interpreting Musical Gestures, Topics, and Tropes: Mozart, Beethoven, Schubert. Bloomington: Indiana University Press.

Hatten, Robert. 2019. "Performance and Analysis - Or Synthesis: Theorizing Gesture, Topics, and Tropes in Chopin's F-Minor Ballade". Indiana Theory Review, 28 (1/2): 45-66.

Johnson, Eric. (1972). “A Composer's Vision photographs by Ernest Bloch”. Aperture, 16 (3), 63. Disponível em: $10.2307 / 24471023$

Knapp, Alexander. 1970-1971. "The Jewishness of Bloch: Subconscious or Conscious?". Proceedings of the Royal Musical Association, 97: 99-112. 
Kushner, David. 2010. "Ernest Bloch. The Cleveland Years". Min-Ad - Israel Studies in Musicology Online, 8(II): 175-200.

Lazar, Aryeh. 2017. "A Reexamination of the Structure of the Inward Outward Upward Prayer Scale". The International Journal for the Psychology of Religion, 27 (3): 141-153. Disponível em: 10.1080/10508619.2017.1313014

Maróthy, Janos. 1993-1994. "Rite and Rhythm. From Behaviour Patterns to Musical Structures". Studia Musicologica Academiae Scientiarum Hungaricae, 35 (4): 421-433. Disponível em: 10.2307/902316

Mayse, Ariel Evan, e Daniel Reiser. 2018. "Territories and Textures: The Hasidic Sermon as the Crossroads of Language and Culture". Jewish Social Studies, 24 (1): 127-160. Disponível em: 10.2979/jewisocistud.24.1.05

Östersjö, Stefan. 2016. “Go To Hell: Towards a Gesture-Based Compositional Practice”. Contemporary Music Review, 35 (4-5): 475-499. Disponível em: 10.1080/07494467.2016.1257625

Robinson, Jenefer, e Hatten, Robert. 2012. "Emotions in Music". Music Theory Spectrum, 34 (2): 71-106. Disponível em: 10.1525/mts.2012.34.2.71

Rubin, Joel. 2005. "Music Is the Pen of the Soul: Recent Works on Hasidic and Jewish Instrumental Klezmer Music". AJS Review, 29 (1): 145-158. Disponível em: 10.2307/4131814

Schleifer, Ronald. 2019. “Modernism as Gesture: The Experience of Music, Samuel Beckett, and Performed Bewilderment". Criticism, 61 (1): 73-96. Disponível em: 10.13110/criticism.61.1.0073

Seroussi, Edwin. 2017. "Shamil: Concept, Practice and Reception of a Nigun in Habad Hasidism". Studia Judaica, 20, 2(40): 287-306. Disponível em: 10.4467/24500100STJ.17.013.8248 